\title{
INTRAVENOUS ZOLEDRONIC ACID FOR PAIN RELIEF IN BONE BRUISING OF THE KNEE: A CASE REPORT
}

\author{
Avinash $\mathrm{P}^{1}$
}

\section{HOW TO CITE THIS ARTICLE:}

Avinash P. "Intravenous Zoledronic Acid for Pain Relief in Bone Bruising of the Knee: A Case Report". Journal of Evolution of Medical and Dental Sciences 2015; Vol. 4, Issue 47, June 11; Page: 8216-8219,

DOI: $10.14260 /$ jemds/2015/1189

ABSTRACT: Bone bruising describes the post traumatic bone marrow changes demonstrated on magnetic resonance imaging (MRI). Isolated bone bruises account for clinical symptoms and may also lead to posttraumatic arthritis. We report a patient with isolated, NSAID resistant, post-traumatic bone bruising who improved with intravenous zolendronic acid.

KEYWORDS: IV Bisphosphonate, Zoledronic acid, bone bruise.

INTRODUCTION: Bone bruising describes the post traumatic bone marrow changes demonstrated on magnetic resonance imaging (MRI). ${ }^{1}$ After trauma to the knee, although bone bruising can occur in isolation, ${ }^{2}$ it is more often seen along with concomitant meniscal, ${ }^{3}$ and ligamentous injuries. ${ }^{4,5}$ Isolated bone bruises were initially thought of as benign. ${ }^{6}$ However, there are recent reports that these patients have persistent pain and delayed recovery. ${ }^{7}$ Bisphosphonates, which are potent inhibitors of bone resorption, also have anti-inflammatory action. ${ }^{8}$ Zoledronic acid is a third generation parenteral bisphosphonate with a high efficacy and favorable toxicity profile. ${ }^{9}$ We report a patient with isolated, NSAID resistant, post-traumatic bone bruising who improved with intravenous zolendronate.

CASE REPORT: A 36 years old man presented with a week's history of pain in the right knee following an injury sustained while playing football. The patient had visual analog scale (VAS: 0-10) pain score of eight. Physical examination revealed antalgic gait, tenderness over the medial femoral and tibial condyles and minimal effusion. Active and passive knee ranges of movement were 0-90 and 0-120 respectively but, pain worsened at end flexion. Anterior and posterior Drawer, Lachman, Mcmurray and varus/valgus instabitity tests were negative. Plain radiographs did not reveal any bony abnormalities. He was treated with non-steroidal anti-inflammatory drugs (NSAIDs), physiotherapy and rest.

At three weeks follow-up, pain and effusion persisted. Pain score on VAS was seven. MRI showed discrete foci of low signal intensity on T1-weighted images and high signal intensity on T2weighted images in the medial femoral condyle. (Fig. 1) Menisci, cruciate and collateral ligaments were normal. A diagnosis of post-traumatic bone bruising was made. Since the pain was NSAID resistant, after full explanation to the patient of the treatment, intravenous zoledronic acid, $4 \mathrm{mg}$ diluted in $100 \mathrm{ml}$ normal saline was infused over 30 minutes. Daily oral calcium supplement of $500 \mathrm{mg}$ and vitamin D of 400 IU were continued. Restricted weight bearing was advised but NSAIDs were discontinued.

He was followed up at six and twelve week intervals. The VAS pain score decreased from three at sixth week to zero at twelfth week, indicating complete pain relief. Knee range of movement also returned to normal. MRI repeated at 12th week showed a significant reduction in the size of bone bruise. (Fig. 2). 
DISCUSSION: In the past, bone bruising was considered as a benign entity without any sequelae and hence the treatment was conservative. However there are reports in the literature documenting the fact that patients with bone bruising have protracted clinical recovery, with more effusions and pain and slower return of motion, than those without evidence of bone bruising. ${ }^{7}$ Further there is also a concern that if these bone bruises are subarticular, they may predispose the overlying cartilage to earlier wear and tear. ${ }^{10}$

Bone marrow edema seen in those with bone bruises is also seen in those with avascular necrosis (AVN), ${ }^{11}$ osteoarthritis (OA).12 and non-traumatic bone marrow edema syndromes. ${ }^{13}$ There is evidence in the literature that this bone marrow edema especially in those with AVN hips and OA does produce pain and along with the reduction of pain the bone marrow edema also reduces. ${ }^{14}$

Bisphosphonates are the back bone of treatment of osteoporosis. Apart from inhibition of osteoclastic resorption, they have also been shown to suppress proinflammatory cytokines such as IL-1, TNF-alpha and IL-6. ${ }^{15}$ We have used oral alendronate, in patients with avascular necrosis and shown that it reduces pain and the need for NSAIDS and helped in the early mobilization of these patients. On follow-up, apart from pain reduction, there was also less bone marrow edema. ${ }^{16}$ Reduction of bone pain with IV bisphosphonates has been observed in patients with metastatic bone disease, corticosteroid induced osteporosis and bone marrow edema syndrome. ${ }^{13}$

Intravenous pamidronate has been used in patients with a variety of painful conditions including vertebral fractures, ${ }^{17}$ and metastasis. ${ }^{18}$ Intravenous zolendronate is more potent and similar in toxicity profile when compared to parenteral pamidronate. ${ }^{19}$ Further unlike pamidronate the infusion can be given quickly and on an outpatient basis.

Our patient had recalcitrant pain in the knees in spite of treatment with optimal doses of NSAIDS for 3 weeks. A single infusion of IV zoledronate led to quick symptomatic recovery and early mobilization. Further there was a significant reduction in the size of the bone bruising on repeat MRI.

CONCLUSION: In conclusion IV zolendronate can be considered in those with bone bruising and recalcitrant pain. There is a need to perform well designed large studies with proper controls on this subject.

\section{REFERENCES:}

1. Mink JH, Reicher MA, Crues JV. 'Magnetic Resonance Imaging of the Knee. New York: Raven Press; 1987: 79-82, 146-7.

2. R. W. Wright, M. A. Phaneuf, T. J. Limbird and K. P. Spindler, Clinical outcome of isolated subcortical trabecular fractures (Bone bruise) detected on magnetic resonance imaging in knees. Am J Sports Med 28 (2000), pp. 663-667.

3. P. A. Kaplan, R. H. Gehl, R. G. Dussault, M. W. Anderson and D. R. Diduch, Bone contusions of the posterior lip of the medial tibial plateau (Contrecoup injury) and associated internal derangements of the knee at MR imaging, Radiology 211 (1999) , pp. 747-753.

4. M. A. Rosen, D. W. Jackson and P. E. Berger, Occult osseous lesions documented by magnetic resonance imaging associated with anterior cruciate ligament ruptures, Arthroscopy 7 (1991), pp. 45-51.

5. M. D. Miller, J. R. Osborne, W. T. Gordon, D. T. Hinkin and M. R. Brinker, The natural history of bone bruises: a prospective study of magnetic resonance imaging detected trabecular microfractures in patients with isolated medical collateral ligament injuries, Am J Sports Med 26 (1998), pp. 15-19. 


\section{CASE REPORT}

6. Mink JH, Deutsch AL. Occult cartilage and bone injuries of the knee: detection, classification, and assessment with MR imaging. Radiology. 1989; 170: 823-829.

7. Davies NH, Niall D, King LJ, Lavelle J, Healy JC. Magnetic resonance imaging of bone bruising in the acutely injured knee-short-term outcome. Clin Radiol. 2004; 59: 439-445.

8. Bianchi M, Franchi S, Ferrario P, Sotgiu ML, Sacerdote P. Effects of the bisphosphonate ibandronate on hyperalgesia, substance $\mathrm{P}$, and cytokine levels in a rat model of persistent inflammatory pain. Eur J Pain. 2007 Jul 28; [Epub ahead of print].

9. Alison M. Massaro. Zoledronic Acid. A Bisphosphonate for Hypercalcemia of Malignancy and Osteolytic Metastases. Cancer Practice 10 (4), 219-221/ Volume 10 Issue 4 Page 219-221, July 2002.

10. D. M. Niall. Bone Bruising Simply a radiological finding or a harbinger of posttraumatic arthritis? Irish Journal of Orthopaedic Surgery and Trauma. Volume 4, Issue 2'99.

11. MR Imaging of Bone Marrow Edema and Joint Effusion in Patients with Osteonecrosis of the Femoral Head: Relationship to Pain. Guo-Shu Huang1, Wing P. Chan2, 3, Yue-Cune Chang4, Cheng-Yen Chang5, Cheng-Yu Chen1 and Joseph S. Yu6 AJR 2003; 181: 545-549.

12. Marco Zanetti, MD, Elisabeth Bruder, MD, José Romero, MD and Juerg Hodler, MD. Bone Marrow Edema Pattern in Osteoarthritic Knees: Correlation between MR Imaging and Histologic Findings. Radiology. 2000; 215: 835-840.

13. J. D. Ringe, Dorst A, Faber H. Effective and rapid treatment of painful localized transient osteoporosis (Bone marrow edema) with intravenous ibandronate. Osteoporos Int. 2005 Dec; (12): 2063-8. Epub 2005 Oct 14.

14. Arnoldi CC, Djurhuus JC, Heerfordt J, Karle A. Intraosseous phlebography, intraosseous pressure measurements and 99mTC-polyphosphate scintigraphy in patients with various painful conditions in the hip and knee. Acta Orthop Scand. 1980; 51: 19-28.

15. Daniele Santini; Maria E. Fratto; Bruno Vincenzi; Annalisa La Cesa; Caterina Dianzani; Giuseppe Tonini. Bisphosphonate Effects in Cancer and Inflammatory Diseases: In Vitro and In Vivo Modulation of Cytokine Activities. BioDrugs, Volume 18, Number 4, 2004, pp. 269-278 (10).

16. S. Agarwala, D. Jain, V. R. Joshi and A. Sule. Efficacy of alendronate, a bisphosphonate, in the treatment of AVN of the hip. A prospective open-label study. Rheumatology 200544 (3): 352359.

17. T. Armingeat, R. Brondino, T. Pham, V. Legré and P. Lafforgue Intravenous pamidronate for pain relief in recent osteoporotic vertebral compression fracture: a randomized double-blind controlled study. Osteoporosis International. Volume 17, Number 11 / November, 2006.

18. Gabriel N. Hortobagyi, M. D. , Richard L. Theriault, D. O. , Lester Porter, M. D. , Douglas Blayney, M. D. , Allan Lipton, M. D. , Clive Sinoff, M. D. Efficacy of Pamidronate in Reducing Skeletal Complications in Patients with Breast Cancer and Lytic Bone Metastases. N Engl J Med. Volume 335: 1785-1792 December 12, 1996 Number 24.

19. Zoledronic Acid Is Superior to Pamidronate in the Treatment of Hypercalcemia of Malignancy: A Pooled Analysis of Two Randomized, Controlled Clinical Trials P. Major, A. Lortholary, J. Hon, E. Abdi, G. Mills, H. D. Menssen, F. Yunus, R. Bell, J. Body, E. Quebe-Fehling, and J. Seaman. Journal of Clinical Oncology, Vol. 19, No 2 (January 15), 2001: pp 558-567. 


\section{CASE REPORT}

Fig. 1: MRI showing discrete foci of high signal intensity on $\mathrm{T} 2$-weighted images in the medial femoral condyle.

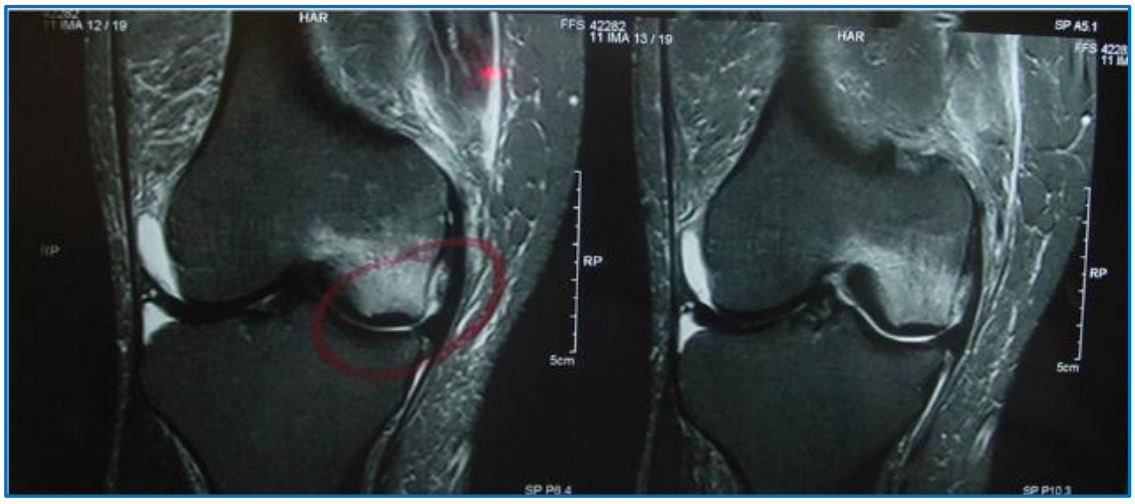

Fig. 1

Fig. 2: MRI repeated at 12 th week showing a significant reduction in the size of bone bruise.

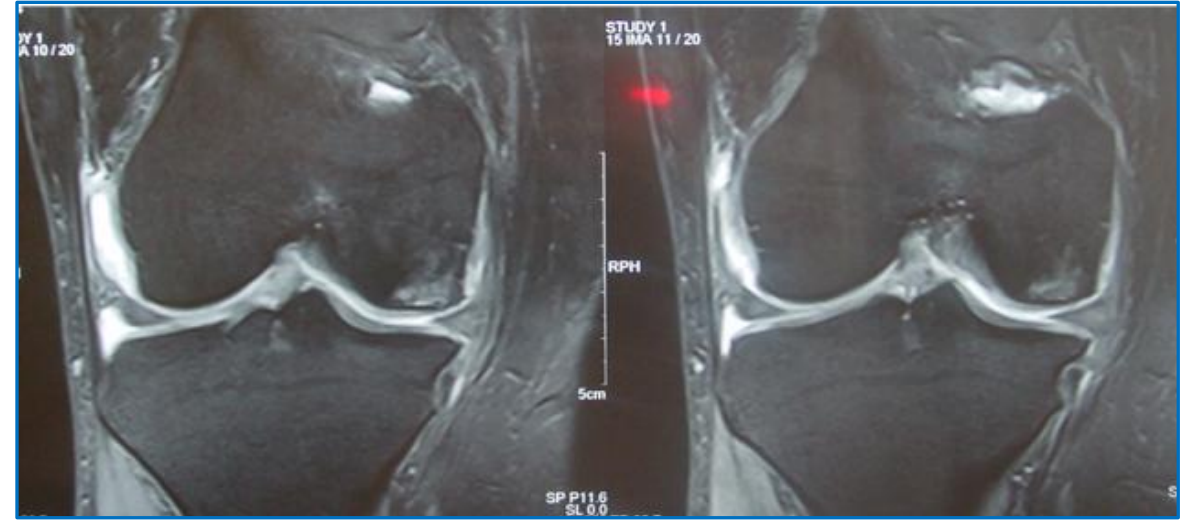

Fig. 2

\section{AUTHORS:}

1. Avinash P.

\section{PARTICULARS OF CONTRIBUTORS:}

1. Assistant Professor, Department of Orthopaedics, Sanjay Gandhi Institute of Trauma and Orthopaedics, Byrasandra, Bangalore.

FINANCIAL OR OTHER COMPETING INTERESTS: None
NAME ADDRESS EMAIL ID OF THE CORRESPONDING AUTHOR:

Dr. Avinash P, Assistant Professor, Department of Orthopaedics, Sanjay Gandhi Institute of Trauma and Orthopaedics, Byrasandra, Jayanagar IV “T” Block, Bangalore-560011.

E-mail:dravinash@hotmail.com

Date of Submission: 15/05/2015.

Date of Peer Review: 16/05/2015.

Date of Acceptance: 04/06/2015.

Date of Publishing: 11/06/2015. 